\title{
A Jatropha biomass as renewable materials for biocomposites and its applications.
}

\begin{abstract}
This review deals with the study of Jatropha biomass as renewable materials for biocomposites and its applications. Jatropha curcas is a multipurpose plant with many attributes and considerable potential. Jatropha plant is cultivated worldwide but it has specific cultivation area in Central and South America, Africa, and South Asia. The Jatropha plant produces many useful products, especially the seed from which oil can be extracted. Extracted oil has similar properties to palm oil and possible to obtain many products after processing. As biomass, Jatropha plant can used as a reinforcement in biocomposite development. Jatropha contain high amount of carbon especially in seed/husk, fruit shell and seed cake and can be used as filler in composite fabrication in the form of carbon black and activated carbon.In this review, we will discuss the distribution of Jatropha around the globe, chemical composition of various parts and extracts of Jatropha and their mechanical and physical properties. We will also cover the use of Jatropha biomass in various technical and biocomposite applications. With the development of green technology, Jatropha latex can be reduced to nanoparticle size. The chemical and physical properties of Jatropha contribute to its applications in food and non-food Products.
\end{abstract}

Keyword: Jathropa; Filler; Biocomposites; Nanoparticles; Applications. 